\title{
Auditory Systems of Opposite-Sex Twins; Twin Study Summaries; In the News; Tribute to Inna Vladimirovna Ravich-Scherbo
}

\author{
Nancy L. Segal \\ Department of Psychology, California State University, United States of America
}

\begin{abstract}
Pesearch comparing the auditory systems of opposite-sex co-twins, homosexual females and bisexual females is reviewed. R Suggestions for how the findings may apply to other populations are provided. Next, recent twin studies of disputed memories and male sexual behaviors are summarized, as are recent events of scientific interest to twin researchers. Finally, a tribute to the late Russian twin researcher Dr. Inna Vladimirovna Ravich-Scherbo is presented.
\end{abstract}

\section{Auditory Systems of Opposite-Sex Twins}

Opposite-sex twin pairs used to be ignored in classic twin research studies. However, nonhuman animal models examining the effects of prenatal exposure to cross-sex hormones have elevated the research status of male-female pairs. For example, vom Saal (1989) showed that in some mammals, the prenatal exposure of females to elevated androgen levels was associated with masculine behavioral and physical characteristics. The wellknown freemartin effect in oppositesex cattle twins has also been of interest — it has been demonstrated that 90\% of female twins in such pairs are sterile due to partial chimerism, the interconnection of blood vessels from fused placentae. Cattle twins (but not human twins) can have single chorions, despite being fraternal, because the dividing chorial membranes fuse and disappear (Gandelman, 1992; see also Segal, 2000).

The implications of such work for opposite-sex human twins have yielded a number of important studies. As most of the findings have been discussed elsewhere, only a brief summary will be presented, followed by a discussion of recent work along these lines, and what we hope to learn in the future.
Resnick et al. (1993) found that males showed greater sensation-seeking tendencies than females, but female twins from opposite-sex pairs scored higher on these measures than females from same-sex pairs. In addition, males usually outperform females on some spatial ability tasks, yet female twins from opposite-sex pairs scored as high as their twin brothers, and better than females from same-sex pairs (ColeHarding et al., 1988). Higher rates of myopia were observed among male-female twins (Miller, 1995), and sets of facial measurements predicting the sex of subjects did not work with opposite-sex twins (Boklage, 1985). Most provocatively perhaps, McFadden (1993) found that females with twin brothers emitted fewer continuous tones (spontaneous otoacoustic emissions, or SOAEs) from their ears relative to other female twins and nontwins, and did not differ in this respect from their twin brothers.

Not all studies have, however, detected behavioral or physical differences between female twins with twin brothers and female twins with twin sisters. Loehlin and Martin (1998) found that age at menarche, age at first pregnancy, menstrual cycle length and body height were only slightly higher for female twins from male-female pairs compared with female twins from same-sex pairs. Christensen et al., (1998) and Rose et al., (2002) failed to find differences in fertility, age at first birth and feminine interests between these two female twin groups. In addition, many of the findings summarized above could be explained with reference to the twins' shared social environment.

A recent paper by McFadden (2002) summarizing work on the auditory systems of opposite-sex twins, homosexual females and bisexual females is provocative and suggests new directions for future research:

1. The emission of SPOEs by female twins with male co-twins appears to be masculinized. However, the emission of SPOEs by male twins with female co-twins does not appear to differ from those of other males.

Address for correspondence: Nancy L. Segal, Department of Psychology, California State University, Fullerton, CA 92834, USA.

E-mail: nsegal@fullerton.edu 
2. SPOE measures of homosexual and bisexual females are shifted in a male direction, compared with those of heterosexual females.

It is difficult to attribute these observed twin and sexual orientation group differences to experiential factors. This is largely because sex differences in SPOEs appear at birth and generally remain stable (although they can be altered in some cases). Therefore, biologically based effects, rooted in individuals' prenatal hormonal environment, seem plausible. McFadden reasoned along these lines, after ruling out certain lifestyle and life history factors that may have been contributory:

1. If the twin and nontwin group differences were present from birth, then it is likely that they were associated with processes underlying sex differences in cognitive and physical traits.

2. Exposure to elevated levels of prenatal androgen may weaken SPOEs in female twins from opposite-sex pairs.

3. The finding that not all measured characteristics associated with atypical hormonal exposure show predicted sex differences may reflect hypothesized 'localized effects'.

This implies that different body structures and neural circuits are linked with the different physical and behavioral traits that have been compared between male and female twins, and between homosexual and heterosexual individuals. These structures and circuits may be differentially affected during development. Specifically, not just the androgen level, but timing of exposure, duration of exposure, and the individuals' sensitivity to circulating hormones may play significant roles.

Further testing of these ideas and the elucidation of prenatal hormonal mechanisms underlying specific behaviors are ambitious tasks. Efforts in this area could help explain many compelling observations, not just differences between dizygotic (DZ) male and female twins, but also between monozygotic (MZ) co-twins, especially pairs differing in sexual orientation and gender identity. Twin registry studies of sexual orientation show heritability estimates of .51 to .67 for males and .23 to .30 for females (see Mustanski et al., 2002).
A recent twin study of gender identity disorder reported a heritability of $62 \%$, based on survey responses from parents of 314 twin pairs, aged from 7 to 14 years (Coolidge et al., 2002). It is possible that despite their genetic identity, MZ co-twins may show subtle differences in hormonal sensitivity and uptake, explaining the twins' less than perfect similarity in these behaviors.

Transsexualism, the perceived lack of agreement between one's physical anatomy and gender identity and the belief that one belongs to the opposite sex, might also benefit from such research. Given the rarity of this behavior, there have been only 17 published case reports involving $\mathrm{MZ}$ twins; seven pairs are concordant (6 male and 1 female) and 10 pairs are discordant (8 male and 2 female; 'Summary of statistics', 2004). In many of these cases (and in two additional pairs recently interviewed by this author), feelings of being a member of the opposite sex were present very early, even as young as 3 years of age. This finding is consistent with the view that prenatal hormonal effects may have been operative.

\section{Twin Study Summaries}

\section{Disputed Memories}

The authors of this study were interested in determining if twins' disputed memories are more mundane than memories that are nondisputed (Kuntay et al., 2004). They obtained narratives provided by $\mathrm{MZ}$ and DZ twins in a related study (see Ikier et al., 2003). These narratives included (1) memories of autobiographical events whose ownership the twins disputed; and (2) memories of autobiographical events which the twins were certain that they experienced individually. Twins also provided brief descriptions of events leading to those memories. In that study, MZ twins were found to have a greater number of disputed memories than $\mathrm{DZ}$ twins.
The disputed memories and personal narratives were presented to judges who rated them on a scale from (1) very mundane to (5) very extraordinary. Disputed memories were rated as more mundane than nondisputed memories. More interesting perhaps is that in the previous study by Ikier at al. (2003), MZ twins showed a higher frequency of disputed memories than DZ twins; an earlier study by Sheen et al., (2001) failed to find a twin group difference in this measure. However, neither of these two studies documented the methods by which the zygosity of the twin pairs was assessed.

If $M Z$ twins do experience a higher frequency of disputed memories than DZ twins, this could reflect their greater average social closeness and intimacy (see Segal, 2000). In fact, this reminded me that I once interviewed very close $\mathrm{MZ}$ female twins who were puzzled over who had had a particular dream ...

\section{Sexual Behavior in Male Twins}

The Vietnam Twin Registry has yielded considerable information about factors underlying behavioral and physical traits. Most recently, Lyons et al. (2004) used members of this registry to assess genetic and environmental contributions to specific sexual behaviors in men: age at first sexual relations and engaging in sexual activity with multiple partners. Data relevant to this project were gathered between 1991 and 1993 as part of the Harvard Twin Study of Drug Abuse. The final 
sample included $1874 \mathrm{MZ}$ twin pairs and $1498 \mathrm{DZ}$ twin pairs.

Half of the twins had engaged in sexual relations at age 17 years or before. Correlations for this measure were .60 for $\mathrm{MZ}$ twins and .44 for

\section{In the News}

\section{Older Mothers of Twins}

In November 2004, a 56-year-old woman, Aleta St. James, delivered opposite-sex twins, Gian and Francesca, in New York City (Catton, 2004). She conceived the twins via in-vitro fertilization on her second attempt. The twins were delivered by Caesarian section as a result of their positioning, but the mother was considered sufficiently fit for vaginal delivery.

For several days Ms St. James was believed to be the oldest mother to conceive and deliver twins successfully. She still may be if cases are restricted to women conceiving artificially: 59-yearold Francis Harris from Sylvester, Georgia, is pregnant with naturally conceived twins ('Woman, 59, shocked', 2004). In addition, her tubes had been tied. Harris already has five children, 14 grandchildren and six great-grandchildren. Her multiple pregnancy was detected when she consulted her physician because of an unexplained weight gain.
DZ twins, and differed significantly. The probandwise concordance rates for having had multiple partners were $36.9 \%$ for $\mathrm{MZ}$ twins and $26.1 \%$ for DZ twins, values that also showed a statistically significant difference. It was estimated that between one quarter and one half of the variance in the measured sexual traits was associated with genetic factors. Only age at initiation of sexual relations showed a shared environmental effect.

\section{Identical SAT Scores}

In October 2004, twins Dillon and Jesse Smith, age 16 years, obtained identical perfect scores of 1600 on the Scholastic Aptitude Test (SAT; 'Long Beach: Twins score perfect 1600', 2004). According to the college board administering these tests, only 939 out of 1.4 million students taking the test in 2004 achieved this score. Earlier in the year, Dillon had scored 1520 and Jesse 1530.

The twins claim to be DZ, but the basis for their judgment is uncertain. It would be more remarkable if the twins were $\mathrm{DZ}$ as opposed to $\mathrm{MZ}$, as $\mathrm{MZ}$ twins show greater average resemblance on mental ability batteries than do DZ twins. The day will hopefully come when hospitals routinely compare the DNA of same-sex infant twins. By doing so they would be helping the families, scientists and the twins themselves in more ways than they could imagine. Specifically, interesting bits of information (like twins' perfectly matched SAT scores) would assume scientific significance.

\section{Conjoined Twins' Surgeons Honored}

In October 2004, 12 New York scientists received the Mayor's Awards for Excellence in Science and Technology (Steinhauer, 2004). These awards, presented by Mayor Michael R. Bloomberg, are decided annually. Drs James T. Goodrich and David A. Staffenberg of the Montefiore Children's Hospital were among the 12 honorees. These physicians were responsible for surgically separating two-year-old conjoined Filipino twins Carl and Clarence Aguirre, who were joined at the head. A relatively new procedure was used in this case the physicians performed four short surgeries over a 10 -month period rather than a single extended operation ('Conjoined twins to be separated', 2004).

\section{Tribute: Inna Vladimirovna Ravich-Scherbo}

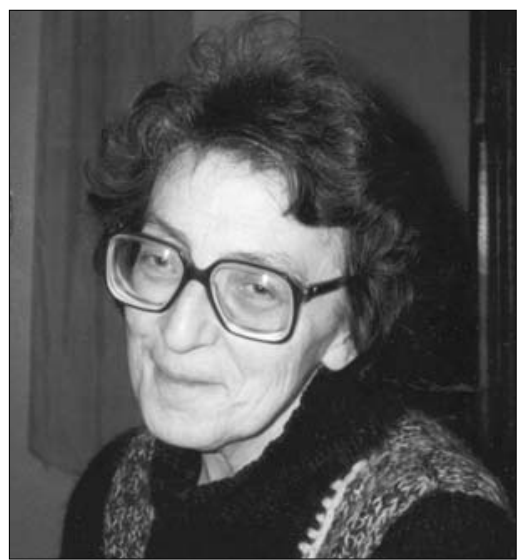

Russian twin researcher Inna Vladimirovna Ravich-Scherbo passed away on October 29, 2004. Aged 77 years, she was born on April 21, 1927. One of her current students, Vladimir Dorfman, provided me with this marvelous tribute, which I have edited lightly:

'Dr. Ravich-Scherbo was an "old school scientist" - she was a devoted scholar, not just a "9:00 am to 5:00 pm scientist". Her life was her research and her research was her life. She kept active in her work, despite her age, and even in her last days she delivered lectures to students at Moscow State University and Russian State University for the Humanities. Her students were always impressed by her sharp mind and intelligence. She has been known by her Russian research colleagues as the number one researcher in the field of differential psychology and psychogenetics in Russia. At the same time, Dr Ravich-Scherbo was a well-balanced, modest and simple person. Most of Dr Ravich-Scherbo's col- 
leagues learned only at her funeral that her personal contributions had been acknowledged at an international level. In 2001, she received a citation from the International Society for Twin Studies. In 2002, Nancy L. Segal and Irina N. Senina published an article, 'Russian Twin Studies: Colleagues, Controversies, Case Studies and Current Events', in the journal Twin Research, a work which will be useful to colleagues who are planning to publish a book honoring the life and work of Dr. Ravich-Scherbo. It is our hope that her long life and fruitful work will be an inspiration for all those sincerely devoted to searching for answers to complex twin questions.'

I had the pleasure of participating in the first Moscow Summer School (human ethology), held in Zvenigorod, in June, 2001. Unfortunately, Dr. Ravich-Scherbo was unable to attend, but we did exchange greetings through her students. While researching and writing my article on Russian twin studies for Twin Research, she graciously agreed to answer my questions via e-mail and an interpreter. A small portion of that interview is reproduced below; the entire text can be found in the original article (Segal \& Senina, 2002):
NS: How did you become interested in twin studies? What exactly made you interested?

RS: I became interested in twins as a method for studying hereditary attributes of the human nervous system. This question (applied to animals) arose in the works of the famous Russian physiologist, I. P. Pavlov. My first student who started this work, N. F. Shliakhta (Department of Psychology at Moscow State University), studied features of the strengths of nerve processes. Others joined her later. The main results are presented in our first collection, Problems of the Genetic Psychophysiology of Humans, published by Nauka (Science) in 1978.

NS: What research activities did you pursue during the years that psychogenetic work was not allowed?

RS: I worked in the laboratory of one of the biggest nativist psychologists, B. N. Teplov. He was also my instructor in graduate school when I studied the attributes of the nervous system using sensory and motor electrophysiologic methods in adults and children, and in children with mental handicap.

NS: In Russia today, what is the most exciting twin study or twin research finding?

RS: Unfortunately, we have a financial situation here which makes it very hard to do much research on twins. That is why there are not many such studies. However, I think they are all very interesting, including the psychophysiologic studies, studies of twins from the first months of life (T. A. Stroganova and collaborators at the Brain Research Institute, and E. A. Sergeenko and collaborators, the Psychological Institute of the Russian Academy of Sciences) and the longitudinal study of twins from preschool to later years (M. S. Egorova and collaborators, at our institute, which is the Psychological Institute of the Russian Academy of Pedagogical Sciences).

In the last few years, colleagues from the medical institute surveyed 135 pairs from 40 to 60 years of age, with reference to blood pressure, daily and nightly blood pressure profile, hypertension, and other measures (A. P. Saharndak, L. I. Kirichenko and collaborators). Among the earlier studies, I would note the psychophysiologic studies of T. M. Mariutina on optically caused potentials, and the work of S. B. Malykh on brain potentials associated with motion. In addition, there is the interesting work by N. V. Gavrish, S. B. Malykh and T. A. Meshkova on EEG spectral characteristics and sex differences in 6- to 7-year-old twin children.

Dr. Ravich-Scherbo will be missed.

\section{References}

Boklage, C. (1985). Interactions between opposite-sex dizygotic fetuses and the assumptions of Weinberg difference method epidemiology. American Journal of Human Genetics, 37, 591-605.

Catton, P. (2004, November 11). New mother of twins shrugs off biological clock. New York Sun, p. 2.

Christensen, K., Basso, O., Kyvik, K. O., Juul, S., Boldsen, J., Vaupel, J. W., \& Olsen, J. (1998). Fecundability of female twins. Epidemiology, 9, 189-192.

Cole-Harding, S., Morstad, A. L., \& Wilson, J. R. (1988). Spatial ability in members of opposite-sex twin pairs. Behavior Genetics, 18, 710.

Conjoined twins to be separated. (2004, August 2). New York Sun, p. 2.
Coolidge, F. L., Thede, L. L., \& Young, S. E. (2002). The heritability of gender identity disorder in a child and adolescent twin sample. Behavior Genetics, 32, 251-257.

Gandelman, R. (1992). Psychobiology of behavioral development. New York: Oxford University Press.

Ikier, S., Tekcan, A., Gulgoz, S., \& Kuntay, A. C. (2003). Whose life is it anyway? Adoption of each other's autobiographical memories by twins. Applied Cognitive Psychology, 17, 237-247.

Kuntay, A. C., Gulgoz, S., \& Tekcan, A. (2004). Disputed memories of twins: How ordinary are they? Applied Cognitive Psychology, 18, 405-413.

Loehlin, J. C., \& Martin, N. G. (1998). A comparison of adult female twins from opposite-sex and same-sex pairs on variables related to reproduction. Behavior Genetics, 28, 21-27.
Long Beach: Twins score perfect 1600 on SATs. (2004, October 28). New York Times, Section B.

Lyons, M. J., Koenen, K. C., Buchting, F., Meyer, J. M., Eaves, L., Toomey, R., Eisen, S. A., Goldberg, J., Faraone, S. V., Ban, R. J., Jerskey, B. A., \& Tsuang, M. T. (2004). A twin study of sexual behavior in men. Archives of Sexual Behavior, 33, 129-136.

McFadden, D. (1993). A masculinizing effect on the auditory systems of human females having male co-twins. Proceedings of the National Academy of Sciences USA, 90, 11900-11904.

McFadden, D. (2002). Masculinization effects in the auditory system. Archives of Sexual Behavior, 31, 99-111.

Miller, E. M. (1995). Reported myopia in opposite-sex twins: A hormonal hypothesis. Optometry and Vision Science, 72, 34-36. 
Mustanski, B. S., Chivers, M. L., \& Bailey, J. M. (2002). A critical review of recent biological research on human sexual orientation. Annual Review of Sex Research, 134, 89-140.

Resnick, S. M., Gottesman, I. I., \& McGue, M. (1993). Sensation seeking in opposite-sex twins: An effect of prenatal hormones? Behavior Genetics, 23, 323-329.

Rose, R. J., Kaprio, J., Winter, T., Dick, D. M., Viken, R. J., Pulkkinen, L., \& Koskenvuo, M. (2002). Femininity and fertility in sisters of twin brothers: Prenatal androgenization? Cross-sex socialization? Psychological Science, 13, 263-267.

Segal, N. L. (2000). Entwined lives: Twins and what they tell us about human behavior. New York: Plume.

Segal, N. L., \& Senina, I. N. (2002). Russian twin studies: Colleagues, controversies, case studies and current events. Twin Research, 5, 53-64.

Sheen, M., Kemp, S., \& Rubin, D. (2001). Twins dispute memory ownership: A new false memory phenomenon. Memory and Cognition, 29, 779-788.
Steinhauer, J. (2004, October 14). Mayor honors achievements of 12 scientists. New York Times, p. B8.

Summary of statistics for identical twins, one of whom becomes transsexual. Retrieved December 16, 2004, from My Genes web site, http://www. mygenes.co.nz/stats.html

vom Sal, F. S. (1989). Sexual differentiation in litter-bearing mammals: Influence of sex of adjacent fetuses in utero. Journal of Animal Science, 67, 1824-1840.

Woman, 59, shocked to learn she'll have twins. (2004, November 12). Los Angeles Times, p. A24. 